\title{
HEALTH SYSTEM RESILIENCE: CONCEPT DEVELOPMENT
}

\author{
Stefka Koeva, Maria Rohova \\ Department of Health Economics and Management, Faculty of Public Health, \\ Medical University-Varna, Bulgaria.
}

\begin{abstract}
:
In the past five-ten years, the international health systems agenda has a noticeable new emphasis, that on resilience. The topic of resilience has gained significant attention among policymakers, international organisations and health system researchers, the 2008 global economic crisis and the Zica and Ebola outbreaks catalysing this effect. It is already considered an essential aspect of health system performance and strengthening.

Much of the knowledge in resilience is informed by insights from other ûelds that have embraced it as a research topic. Having originated as a construct in mechanical engineering and psychology, the resilience approach has been borrowed comparatively more recently by a variety of other fields. The aim of the current study is to explore the concept development on a broader level that goes beyond the health care sector. A comprehensive literature review was carried out in April-May 2019. Searches for peer-reviewed articles were conducted in the databases Scopus, PubMed, ScienceDirect, and WHO library. An additional grey literature search was conducted with a focus on publications by international, non-governmental organisations and think tanks. Among the plethora of fields approaching the concept, three strands stand out as underlying the more recent health systems resilient thought - ecological and social-ecological systems, climate change and disasters and organisational theory. The study traces the development of the concept of resilience in these different 'schools' and its impact on health systems resilience theory.
\end{abstract}

Keywords: resilience, disasters, climate change, ecological systems, social-ecological systems, organisational theory,

\section{BACKGROUND}

The way we think about health systems, define and frame them evolves and develops with time. The new challenges and adverse effects that society faces give impetus to new knowledge and ideas. As undesirable as the shocks, crises, disruptive events and stresses are, they stimulate our efforts to comprehend the system better, to get to know the kinds of disturbances it can endure, its capacity to react and adapt and, eventually, to transform.

In the past five-ten years, the international health systems agenda has a noticeable new emphasis, that on resilience. It is a comparatively recent addition to the health sys- tem language. The topic of resilience has gained significant attention among policymakers, international organisations and health system researchers. The 2008 global economic crisis and the Zica and Ebola outbreaks were a catalyst to this effect. Health system resilience is often defined as "the capacity of health actors, institutions, and populations to prepare for and effectively respond to crises; maintain core functions when a crisis hits; and, informed by lessons learned during the crisis, reorganise if conditions require it" [1]. A resilient health system is one able to absorb stresses and shocks, adapt to changes and transform if needed $[2,3$, $4,5,6,7]$.

Much of the knowledge in resilience is informed by insights from other ûelds that have embraced it as a research topic. Given the existing impressive body of resilience across the fields and the rich multidisciplinary context of the concept, the health and health system researchers have had the opportunity to build on the accumulated knowledge of the topic in domains outside health and healthcare. Having originated as a construct in mechanical engineering and psychology, the resilience approach has been borrowed comparatively more recently by a variety of other fields. Over the past decade, the notion of resilience has spread to various branches of human knowledge, disciplines, sectors and activities. It has been explored in a broad array of scholarly disciplines and has emerged as a salient paradigm in ecology and environmental sciences, social-ecological systems, disaster risk reduction and disaster management, natural hazards and land use planning, climate change, urban and rural studies, geography, economics, food and nutrition security. It has been examined from various perspectives: social organisations and institutions (organizational and institutional resilience), infrastructure (infrastructure resilience), networks (network resilience) and others. The concept is increasingly used in scientific research and scholarly literature across disciplines (published in the Web of Science platform), but the rise is impressive - nine-fold between 1997 and 2015 [8].

In this context, our research question is how to understand and interpret the literature addressing the topic of resilience. More specifically, we are interested in the way resilience has been defined in general and in the health care context. The analysis anchor is the existing body of research conceptualising resilience. The aim of the current study is to explore the concept development on a broader level. A comprehensive literature review was carried out in April-May 2019. Searches for peer-reviewed articles were conducted in 
the databases Scopus, PubMed, ScienceDirect, and WHO library. An additional grey literature search was conducted with a focus on the international organisations' publications, documents published online or in print (World Health Organisation, Organisation for Economic Co-operation and Development), as well as by non-governmental organisations and think tanks. Generic search engines Google Scholar and Google Advanced Search were also used to identify studies otherwise omitted.

\section{REVIEW RESULTS}

\section{The precursors}

As evident from the simplest reference with the dictionary, initially the two meaning of the word "resilience" concern the physical world and objects: "the ability of a substance to return to its usual shape after being bent, stretched, or pressed" (Cambridge Dictionary); "the capability of a strained body to recover its size and shape after deformation caused especially by compressive stress" (Merriem-Webster Dictionary) and an innate human capacity: "to be happy, successful, etc. again after something difficult or bad has happened" (Cambridge Dictionary); "to recover from or adjust easily to misfortune or change" (Merriem-Webster Dictionary).

In physics and mechanical engineering, it is considered to be the property of a material to resist shocks, absorb energy and hold under elastic strain before permanent distortion or failure. It is not surprising, then, that some of the attempts to model organisations' resilience have been based on analogies from the material performance and the way mechanical substance react and stretch (strain) in response to stress [9]. And the second most common dictionary connotation of the label "resilience", related to the human beings, underlies a part of psychology, which for more than four decades has grasped and developed resilience research in the context of the individual who, faced with "adversity, trauma, tragedy, threat or even significant stress" [10], copes with them, continues functioning and adapts well. Psychological resilience is a developmental and psychosocial process through which individuals, exposed to adversity or potentially traumatic events, undergo psychological adaptation over time [11].

Psychological resilience research originated in two fields: traumatology (looking at adults) and developmental psychology (looking at children and youth). The early stages of research explicitly related to developmental psychology and the resilience capacity in children and young people. For many decades, researchers have endeavoured to enhance understanding of the children who having been exposed to significant stress of traumatic occurrences managed to manifest healthy adaptive behaviour. Developmental psychologists conceptualise resilience "as a dynamic developmental process encompassing the attainment of positive adaptation within the context of significant threat, severe adversity or trauma" [12]. The critical point emphasised by the researchers is the achievement of normal functioning and development despite the difficulties endured and stressful experiences. Lately, the resilience field within child development undergoes a significant evolution aiming at the more inter- disciplinary and synergetic approach to resilient functioning, with more considerable attention to issues of timing, process, and context of change and adaptability; and translation of the accumulated robust scientiûc knowledge into a set of best practices for prevention and effective interventions [13].

In the other filed with rich experience of resilience studies, psychotraumatology, there is also a noticeable tendency of integration of all relevant concepts and insights of resilience theory from the field of neuroscience, mental health, medicine, psychology, which has started to foster a noticeable paradigm shift toward enhancing resilience [14]. In general, in the latest of psychological resilience research resilience is viewed as a process which develops and change over à lifetime and with the change of circumstances; including different mechanisms with intricate, interdependent relationships; less about problems people have when faced with adversity and more about coping successfully, positive adaptation and growth, a "steady trajectory of health functioning" $[11,14]$.

\section{The immediate anticipator 'schools'}

As the resilience theme has been approached by health systems community comparatively at a later stage, much of the present-day understanding and expertise in resilience conceptualisation in health at a system/societal level has been borrowed from other areas. But given the general interrelation and interaction of dynamic systems across various scales and the tendency of mutual exchange of knowledge and conceptions, the construct illustrates very well the benefits from the joint efforts and useful idea-sharing, bringing to the health sector a lot of useful insights from other sectors. Among the plethora of fields approaching the concept, three strands ('schools') stand out as underlying the more recent health systems resilient thought. cal systems

The resilience of ecological systems or socio-ecologi-

The first attempts to capture and conceptualise the property of the ecosystem to withstand changes and still preserve its basic functioning date back to the 1970s with the work of theoretical ecologist C.S. Holling. Addressing the ecosystem's dynamics, he introduced the word "resilience" into the ecological literature in his 1973 work, now recognized as seminal, "Resilience and Stability in Ecological Systems". In it, he describes resilience as a characteristic, responsible for the persisting relationships within systems, which is a measure of "the ability of these systems to absorb changes of state variables, driving variables, and parameters, and still persist" [15]. The definition is further elaborated in his own and other studies as the capacity of a system to absorb external stresses and endure, before changing its structure functions and control [16], and is measured by "the amount of disturbance that an ecosystem could withstand without changing self-organised processes and structures" [17]. It describes the degree to which the system is capable of self-organisation, learning and adaptation $[15,18]$.

With the very introduction of the concept of resilience was proposed, the difference between the stable-state resilience or single/near-equilibrium resilience and the resilience 
in complex systems. This distinction is of fundamental methodological importance as it marks the bridging between resilience and the complex adaptive systems, which is one of the significant characteristics of health systems resilience. If resilience is defined as simply as the ability to resist perturbation and the rate with which it returns to equilibrium or a steady-state following the disturbance, implicit is the understanding of global stability or single equilibrium. This type of reasoning is very much in the tradition of engineering, and Holling calls this resilience "engineering resilience" [16]. It presents a very simplified version of a system, characterised by the efficiency of function, the constancy of the system and predictability of its behaviour and outcomes. The second type of resilience emphasises unsteady conditions, dynamism, non-linearity, the existence of "multiple stability domains and the tolerance of the system to perturbations that facilitate transitions among stable states" [17]. This type of resilience measured by "the magnitude of disturbance that can be tolerated before a system moves into a different region of state space and a different set of controls" [19] is called by Holling "ecological" [16]. Complex systems are continuously developing, non-linear, exhibiting cross-scale interdependencies and dynamics. They are uncertain and unpredictable.

The researchers of socio-ecological resilience emphasise another important point. Resilience as a 'buffer capacity' allowing persistence or robustness or "the capacity of a system to absorb disturbance and reorganise while undergoing change so as to still retain essentially the same function, structure, identity and feedbacks" [18] does not exhaust its meaning. The theoretical construct proposed by the socio-ecologists, in addition, incorporates the possibility of reorganisation, the idea of adaptive capacity, which emerges from the system's self-organisation. The perturbations can open up opportunities and new trajectories of development that have not existed. One more insight, which has a specific reference to the health system resilience, does not necessarily lead to a more desirable state: the balance between sustainability and change can be very subtle [18, 20].

Thus, the resilience perspective has advanced with the more profound and developed understanding of the socioecological systems as complex adaptive systems. In the course of the development and framing, the resilience construct theorists came to a fuller understanding the interconnectedness between humans and nature and interdependences between ecosystem and social dynamics introduced the term "socio-ecological system" as a specific conceptual entity. According to the Resilience Alliance, a multidisciplinary research and policy network, inspired by Holling's work, as applied to ecosystems, or integrated systems of people and the natural environment, resilience is characterised by the following defining features: 1) It is "the capacity of a social-ecological system to absorb or withstand perturbations and other stressors"; 2) The system "remains within the same regime, essentially maintaining its structure and functions"; 3) "It describes the degree to which the system is capable of self-organisation, learning and adaptation" $[15,18,21]$.

To sum up, the socio-ecological research is essential in clarifying the following key components of the resilience construct, which has been relevant to the conceptualisation of the health systems resilience:

1) The presence of perturbation (disturbance, stress) affecting the system.

2) The existence of a capability/ability of the system to resist or absorb disturbance (to remain within the same regime, substantially maintaining its structure and functions) before it changes its structure and functions.

3) Resilience is a 'buffer capacity', demonstrating robustness.

4) It is measured by the amount/magnitude of disturbance, which can be tolerated before the system moves to a different state.

5) In addition, it incorporates the possibility of reorganisation, the idea of adaptive capacity. Resilience as the capacity of a dynamic system to adapt successfully.

6) The disturbances can offer new opportunities for development and reconfiguration.

7) Resilience does not necessarily mean moving to a better state.

8) The resilience perspective has advanced with the adoption of the complexity approach.

In general, the scholarly achievement of the socio-ecological school of resilience is that it not only explicitly develops and frames the theoretical concept, it introduces and establishes a resilience approach and frame of mind, which relates this construct to the complex adaptive systems: 1) how they persist through continuous development when faced with challenges and change; and 2) how they transform and reconfigure in a more desirable way [20].

Climate change and disaster resilience (risk reduction)

The studies of socio-ecological systems and resilience made possible the natural transition to the research of the behaviour of a whole range of social systems in a variety of settings. Much of the push for this extension of the relevance of the concept came from climate change themes and associated with natural disasters. However, the research inevitably started including various types of manmade disasters threats, catastrophes, hazards - all domains where the issues of vulnerability and risk are essential. Here, again, the number and variety of definitions and frames are overwhelming. A more detailed assessment and comprehensive analysis of climate change and disaster resilience definitions is beyond the scope of this review. We address the conceptualisation by the disaster field only insofar as it provides a good starting point for the comparatively more recent health system 'school'. But even a non-exhaustive look at the definitions reveals a gradual refinement and enrichment in the way the notion has been viewed, and its meaning developed.

Usually, in the earlier studies, the conceptualisations of resilience refer to a system's ability to (fully) recover after a shock or disaster $[22,23]$. The emphasis is on the ability of a system to maintain its functions and structure when faced by hazards, to return to a previous status, 'bounce back' and survive and cope. According to Longstaff et al. it is "the capacity of a system to absorb disturbance, undergo change, 
and retain essentially the same function, structure, identity, and feedbacks" [24]. In this understanding, resilience is reduced to "coping", defined as "the ability of people, organisations, and systems, using available skills and resources, to face and manage adverse conditions, emergencies or disasters" [25]. According to Gilbert, "resilience is defined as the ability to minimise the costs of a disaster, to return to a state as good as or better than the status quo ante, and to do so in the shortest feasible time. As such, greater resilience entails a return to some 'normal' as soon as possible, and the best 'normal' reasonably achievable. Resistance is used to mean the ability to withstand a hazard without suffering much harm. Resilience ... include resistance but will also include the ability to recover after suffering harm from a hazard" [26]. Similarly, Bruneau et al. define resilience as "the ability of social units ... to mitigate hazards, contain the effects of disasters when they occur, and carry out recovery activities in ways that minimize social disruptions and mitigate the effects of future (disasters)" [27].

In recent years, the definitions have become much more detailed, with greater attention to the breakdown of the concept into separate components and extension of its meaning beyond the simple 'bouncing back'. The more developed approach is evident in the following definition: " $A$ multi-dimensional construct, resilience is defined as the capacity of individuals, families, communities, systems, and institutions to anticipate, withstand and/or judiciously engage with catastrophic events and/or experiences; actively making meaning with the goal of maintaining normal function without fundamental loss of identity" [28]. Another author views disaster resilience "as the intrinsic capacity of a system, community or society predisposed to a shock or stress to adapt and survive by changing its non-essential attributes and rebuilding itself' [29]. The Building Resilience and Adaptation to Climate Extremes and Disasters - one of the most extensive resilience programmes globally, funded by Department for International Development (United Kingdom), defines resilience as the "ability to anticipate, avoid, plan for, cope with, recover from and adapt to (climate-related) shocks and stresses" [30].

Resilience now forms a key element of the United Nations International Strategy for Disaster Reduction (UNISDR). Within the United Nations system resilience is thought of as "the capacity of a system, community or society potentially exposed to hazards to adapt, by resisting or changing, in order to reach and maintain an acceptable level of functioning and structure" [31]. One of the strategic goals of the 2005 Hyogo Framework for Action is to "build resilience to hazards", adding to the definition cited above that resilience "is determined by the degree to which the social system is capable of organising itself to increase this capacity for learning from past disasters for better future protection and to improve risk reduction measures" [31]. The inclusion of the concept in this international framework confirmed that the theme gained prominence both theoretically and practically in the disaster risk reduction discourse. Ten years later resilience remained a salient topic in the Sendai Framework for Disaster Risk Reduction 2015-2030, the "strengthening of resilience" being explicitly empha- sised as a strategic goal of "preventing new and reducing existing disaster risk" by reducing "hazard exposure and vulnerability to disaster" and increasing "preparedness for response and recovery" [32].

The 2012 definition of the Inter-Governmental Panel on Climate Change (IPCC) is "the ability of a system and its component parts to anticipate, absorb, accommodate, or recover from the effects of a potentially hazardous event in a timely and efficient manner, including through ensuring the preservation, restoration, or improvement of its essential basic structures and functions" [33]. Later, the definition is slightly changed: "the capacity of social, economic and environmental systems to cope with a hazardous event or trend or disturbance, responding or reorganising in ways that maintain their essential function, identity and structure, while also maintaining the capacity for adaptation, learning and transformation" [34]. An impetus to the understanding of resilience not only as readiness and responsiveness but also as revitalisation was given by Rodin's work "The Resilience Dividend" where she views and defines resilience as the capability of an entity - "community, an organisation, or a natural system - to prepare for disruptions, to recover from shocks and stresses, and to adapt and grow from a disruptive experience" [35].

A similar logical construction of the concept with greater preference for the detail can be found in the following definition: "The ability of households, communities and nations to absorb and recover from shocks (shocks reflect both infrequent catastrophic events that characterise intensive risk, and, frequent low-impact events that characterise extensive risk and which may cumulatively have great impacts over time), whilst positively adapting and transforming their structures and means for living in the face of longterm stresses, change and uncertainty" [36]. Here, the exposure to extraordinary one-time, short-term shocks as part of the hazards provoking the resilience are complemented by more slow but with high negative pressure adverse events and stresses which can strain the system. The other new elements in the definition are the introduction of change and uncertainty as stressors and the introduction in the definition the possibility of transformation of the system. The latter conceptualisation has been adopted by the OECD in its Guidelines for Resilience Systems Analysis [37].

As the review of the literature demonstrates, the concept has been subject to a wide range of interpretations there are considerable variations in how resilience has been defined. Definitions vary depending on the object of analysis (e.g., individual, facility, asset, organisation/institution, community/region, urban/rural, society/system). Even when attention is focused on a specific object of analysis (e.g., community), definitions may vary in substantive ways.

Disaster resilience studies exist at multiple levels or scales. For the needs of the resilience system analysis, the OECD explicitly outlines five levels: individual, household, community, regional, national [37]. But broadly speaking they can be grouped at three levels/scales: individual, community/organisational/regional and large-scale (national, global) systems or larger systems (system of systems) [38].

Besides, two broad approaches to defining resilience 
can be observed: as an outcome or as a process [29]. The former definitions emphasise the end result (although the inclusion of some path to this outcome is inevitable). The return to the previous state, how quickly the system recovers from failure; the time of the recovery ("the shortest feasible time"); the cost of return ("without much harm") - is what matters in these definitions. The resilience incorporates the capacity to contain the disruption, minimise losses, and restore 'normal' functioning. The latter category - resilience as a process - embraces definitions, which focus on the process "linking a set of adaptive capacities to a positive trajectory of functioning and adaptation after a disturbance" [22]. The orientation on the process, the path to achieving certain outcomes would include more than 'coping', the idea of adaptation, self-organisation, learning and evolving, not simply mitigating the impact of the shock but improving the status-quo. Some researchers view the question of learning and adaptation as critical for resilience [39].

A third approach has emerged recently, which solves the tension in the outcome vs process perspectives by integrating the two: resilience as a construct contains both static and dynamic properties [40, 41]. It can be viewed as "an inherent resilience", a state or "outcome", which resides in the status-quo. It characterises the system's performance at 'normal' times before a disaster strikes. It is this "antecedent" condition or "latent attribute", which enables the "bouncing back" [41]. Cutter et al. call this "a snapshot in time or as a static state" [40]. At the same time, resilience has another dimension of dynamism, which is finding expression in the adaptive properties in the time of the adversary event. This is its process aspect. It allows the system to face the changes and adapt to them. Another way to describe this dichotomy of "outcome and process", of static and dynamic interpretation, is "reactive and proactive" resilience [42]. The two perspectives are theoretically delineated as opposites for analytical purposes. In any real complex system, however, there is likely to be a mixture of the two.

From another perspective, the definitions can be generally divided into a group focusing on only "post-event" actions and a group including "pre-and-post" adverse event components. The former tend to emphasise the reaction to the disturbance. The latter would include the capacity to resist, tolerate, prepare for, and anticipate [23]. One proposed definition of the second type is that "resilience within hazards research is generally focused on engineered and social systems, and includes pre-event measures to prevent hazard-related damage and losses (preparedness) and postevent strategies to help cope with and minimise disaster impacts" [40].

The conceptual research of climate change and disaster resilience reveals the emergence of several insights, which can be of interest when developing the notion of health system resilience:

1) There has been a transition in the studies of resilience from the natural world and ecosystems to the social systems, the social-ecological resilience serving as a bridge or " $a$ boundary object" [43] between the two. The new strand of research focuses on the response to change and negative effects of different character by various groups of humans, calling it "social resilience" defined as "the ability of groups or communities to cope with external stresses and disturbances as a result of social, political and environmental change" [44].

2) The scope, breadth and depth of the definitions change and evolve. The concept is getting more dynamic, reflecting and recognising the complexity of the systems. The earlier research defined resilience to disasters - natural and manmade - more as the capacity of social units: people, organisations and large-level systems, to face and absorb disturbances, recover and preserve normal functioning. Resilience is conceived more like a reaction, a response, a rebound to a disturbance, an "after-the-event" phenomenon. Most of the latest definitions are substantively broader and more complex, the mechanisms including resistance, protection, preparedness, adaptation, transformation [23].

3) Seen from another angle, substantively the construct is undergoing from outcome-oriented to more process-oriented interpretations or to understanding, which involves the integration of the two perspectives. In addition to coping and mitigating the effects of the shocks and stress, the concept now involves the idea also of social learning and strengthening of the social entity, which is a prerequisite for a stronger response in the future. Such an understanding emphasises the forward-looking elements [33].

4) As a whole, the conceptualisation of the resilience of social units is getting increasingly broader and more complex, the evolution of the concept taking account of the complexity of the social systems - the existence of dynamism, uncertainty, non-linearity, unpredictability.

5) In accordance with this development the lexicon of the resilience models also changes: as a reaction to the hazardous events, the system and its component parts "anticipate", "accommodate", "withstand", "judiciously engage", "prepare", "self-organise", "plan for", "adapt", "learn", "change", "improve", "transform".

\section{Organisational/institutional resilience}

This aspect of resilience at the meso-level comprises predominantly various organisations (firms, corporations, enterprises, businesses, various institutions) and develops within organisation and risk management theory [45, 46, 47, $48,49]$. The concept of organisational resilience draws on the more general definitions of resilience but within the specific context of organisational structure, logic and behaviour. The reason we briefly outline it here is that much of the literature on resilience in the health sector is a variation and extension of this type of understanding.

In organisational literature, resilience usually refers to capacities of the organisations to cope with, withstand, absorb strain when faced with adversity, adapt and recover their structure and functionality. Dalziell et al. use the term to describe "the overarching goal of a system to continue to function to the fullest possible extent in the face of stress to achieve its purpose, where resilience is a function of both the vulnerability of the system and its adaptive capacity" [45].

Viewed from the specific perspective of risk management in the face of various threats (terrorist, disease outbreak) and defined more technically resilience is conceived 
as "the ability of the system to withstand a major disruption within acceptable degradation parameters and to recover within an acceptable time and composite costs and risks" [50]. Vogus and Sutcliffe define resilience as "the maintenance of positive adjustment under challenging conditions such that the organisation emerges from those conditions strengthened and more resourceful" [48], carefully characterising the adversity factors as both exogenous to the organisation, coming from its environment - risks, shocks of various character, including the competition, hazards, sudden upsurge in demand - as well as endogenous such as strain, disruptions of standard practices, stresses and pressures due to rapid change, faulty leadership [51]. The inclusion of the internal set of threats in the challenging conditions is explained by the possibility of accumulating minor breaches turning into major disasters infringing the resiliency of the organisational system [52].

Another strand of organisation theory which studies resilience is "the resilience engineering" perspective a paradigm for safety management. Woods gives the following definition: "The ability to recognize and adapt to handle unanticipated perturbations that call into question the model of competence, and demand a shift of processes, strategies and coordination" [46, 47]. Thus, an (organisational) system is considered resilient if "it can adjust its functioning prior to, during, or following events (changes, disturbances, and opportunities), and thereby sustain required operations under both expected and unexpected conditions" [49]. The understanding of resilience in organisational theory is broader than the original conventional meaning. In addition to the response to the risk and unfavourable developments, à significant part of the attributes of resilience are related to the period prior to the occurrence of the adverse events: it involves the "anticipation", "recognition" of the challenges, "creation of foresight" and

"learning from past failures and successes alike" [47]. This perspective to resilience through the lens of safety management is particularly rewarding when exploring and assessing various aspects of patient safety in health care organisations.

\section{CONCLUSION}

Research on health system resilience is still in the explorative stage, especially the way it is modelled and translated into indicators to be tested. Although the body of literature on resilience is growing, the nature of this construct, theoretical underpinning, defining characteristics, drivers and enablers, country-specific context, different dimensions and even less so, its operationalisation, the indicators to measure the resilience capacity of the system, remain insufficiently explored. The conceptualisation of health system resilience that goes beyond the normative interpretation of the concept is still not sufficiently developed.

Although health system resilience is an emerging concept in health care studies, it has already gained valuable insights from other fields. Much of the essential characteristics of resilience has been explored in the context of climate change, disasters, psychology, organisational theory, ecology, etc. The existing knowledge in these areas enables the prompt development of the concept in health care. The complexity of the adaptive systems is taken into account by exploring the resilience of social-ecological systems and health systems resilience theory can borrow much from this approach.

\section{Abbreviation:}

IPCC - Inter-Governmental Panel on Climate Change

OECD - Organisation for Economic Co-operation and

\section{Development}

UNISDR - United Nations International Strategy for

Disaster Reduction

WHO - World Health Organisation

\section{REFERENCES:}

1. Kruk ME, Myers M, Varpilah ST, Dahn BT. What is a resilient health system? Lessons from Ebola. Lancet. 2015 May 9;385(9980):1910-2. [PubMed] [Crossref]

2. Kieny MP, Dovlo D. Beyond Ebola: a new agenda for resilient health systems. Lancet. 2015 Jan 10; 385(9963):91-2. [PubMed] [Crossref]

3. Ager AK, Lembani M, Mohamme A, Ashir GM, Abdulwaha A, de Pinho $\mathrm{H}$, et al. Health service resilience in Yobe state, Nigeria in the context of the Boko Haram insurgency: a systems dynamics analysis using group model building. Confl Health. 2015 Oct 5; 9:30. [PubMed] [Crossref]

4. Ammar W, Kdouh O, Hammoud R, Hamadeh R, Harb H, Ammar Z, et al. Health system resilience: Lebanon and the Syrian refugee crisis. J Glob Health. 2016 Dec;6(2):020704. [PubMed] [Crossref]

5. Ozawa S, Paina L, Qiu M. Exploring Pathways for Building Trust in Vaccination and Strengthening Health System Resilience. BMC Health Serv Res. 2016 Nov 15;16(Suppl 7):639. [PubMed] [Crossref]

6. Witter S, Pavignani E. Review of Global Fund investments in resilient and sustainable systems for health in challenging operating environments. Report for Global Fund for AIDS, Tuberculosis and Malaria. Geneva; 2016. [Crossref]

7. Blanchet $\mathrm{K}$, Nam SL, Ramalingam B, Pozo-Martin F. Gov- ernance and Capacity to Manage Resilience of Health Systems: Towards a New Conceptual Framework. Int J Health Policy Manag. 2017 Aug 1; 6(8):431-35. [PubMed] [Crossref]

8. Lovell E, Bahadur A, Tanner T, Morsi H. Resilience: the big picture " top themes and trends. London: Overseas Development Institute; 2015. [Internet]

9. Woods DD, Wreathall J. Stressstrain plots as a basis for modelling organizational resilience. In: Hollnagel E, Nemeth C, Dekker S (Eds.). Resilience engineering: remaining open to the possibility of failure. Ashgate studies in resilience engineering. Aldershot, UK: Ashgate Publishing; 2008, pp 145-161. 
10. American Psychological Association. The road to resilience. Washington DC: American Psychological Association; 2014.

11. Graber R, Pichon F, Carabine E (Eds.). Psychological resilience. State of knowledge and future research agendas. Working Paper 425. London: Overseas Development Institute; 2015. [Internet]

12. Cicchetti D. Resilience under conditions of extreme stress: a multilevel perspective. World Psychiatry. 2010 Oct;9(3):145-54. [PubMed] [Crossref]

13. Panter-Brick C, Leckman JF. Editorial commentary: Resilience in child development - interconnected pathways to wellbeing. J Child Psychol Psychiatry. 2013 Apr;54(4): 333-6. [PubMed] [Crossref]

14. Southwick SM, Bonanno GA, Masten AS, Panter-Brick C, Yehuda R. Resilience deûnitions, theory, and challenges: Interdisciplinary perspectives. Eur J Psychotraumatol. 2014 Oct 1;5. [PubMed] [Crossref]

15. Holling CS. Resilience and stability of ecological systems. Ann Rev Ecol Syst. 1973 Nov;4:1-23. [Crossref]

16. Holling CS. Engineering resilience versus ecological resilience. In Schulze PE (Ed.). Engineering within ecological constraints. Washington DC: National Academy Press; 1996, pp. 31-43.

17. Gunderson LH. Ecological resilience - in theory and application Ann Rev Ecol Syst. 2000 Nov;31:42539. [Crossref]

18. Walker B, Holling CS, Carpenter SR, Kinzig A. Resilience, adaptability and transformability in socialecological systems. Ecol Soc. 2004; 9(2):5. [Internet]

19. Carpenter S, Walker B, Anderies JM, Abel N. From metaphor to measurement: resilience of what to what? Ecosystems. 2001; 4:765-81. [Crossref]

20. Folke C. Resilience: the emergence of a perspective for social-ecological systems analyses. Glob Environ Chang. 2006 Aug;16(3):253-67. [Crossref]

21. Resilience Alliance. Key concepts: Resilience. 2019. [Internet].

22. Norris FH, Stevens SP, Pfefferbaum B, Wyche KF, Pfefferbaum
RL. Community resilience as a metaphor, theory, set of capacities, and strategy for disaster readiness. Am J Community Psychol. 2008 Mar;41(12):127-50. [PubMed] [Crossref]

23. Carlson JL, Haffenden RA, Bassett GW, Buehring WA, Collins III MJ, Folga SM, et al. Resilience: theory and application. Technical Report. Argonne: Argonne National Lab; 2012. [Crossref]

24. Longstaff PH, Armstrong NJ, Perrin K, Parker WM, Hidek MA. Building resilient communities: a preliminary framework for assessment Homel Sec Aff. 2010 Sep;6(3):6. [Internet]

25. United Nations International Strategy for Disaster Reduction/ UNISDR. Terminology: basic terms of disaster risk reduction. Geneva: United Nations Office for Disaster Risk Reduction; 2009. [Internet]

26. Gilbert SW. Disaster resilience: a guide to the literature. NIST Special Publication 1117. U.S. Department of Commerce, National Institute of Standards and Technology. 2010. [Internet]

27. Bruneau M, Chang SE, Eguchi RT, Lee GS, O'Rourke TD, Reinhorn AM et al. A framework to quantitatively assess and enhance the seismic resilience of communities. Earthq Spectra. 2003 Nov;19(4):733-52. [Crossref]

28. Almedom AM. Resilience research and policy/practice discourse in health, social, behavioral, and environmental sciences over the last ten years. Afr Health Sci. 2008 Dec;8(Suppl 1): S5-13. [PubMed]

29. Manyena SB. The concept of resilience revisited. Disasters. 2006 Nov;30(4):433-50. [Crossref]

30. Bahadur AV, Peters K, Wilkinson E, Pichon F, Gray K, Tanner $\mathrm{T}$. The 3As: tracking resilience across BRACED. Working Paper. London: Overseas Development Institutes; 2015. [Internet]

31. United Nations International Strategy for Disaster Reduction/ UNISDR. Hyogo Framework for 20052015: building the resilience of nations and communities to disasters. Geneva: United Nations Office for Disaster Risk Reduction; 2005. [nternet]

32. United Nations International
Strategy for Disaster Reduction/ UNISDR. Sendai Framework for disaster risk reduction 2015-2030. Geneva, Switzerland: United Nations Office for Disaster Risk Reduction; 2015. [nternet]

33. Intergovernmental Panel on Climate Change/ IPCC. Managing the risks of extreme events and disasters to advance climate change adaptation. Cambridge: Cambridge University Press; 2012. [Internet]

34. Intergovernmental Panel on Climate Change/ IPCC. Glossary. In: Field CB, Barros VR, Dokken DJ, Mach KJ, Mastrandrea MD, Bilir TE, et al. (Eds.). Climate change 2014: impacts, adaptation, and vulnerability. Part A: Global and sectoral aspects contribution of Working Group II to the Fifth Assessment Report of the Intergovernmental Panel on Climate Change. Cambridge, UK \& New York, USA: Cambridge University Press; 2014.

35. Rodin J. The resilience dividend: being strong in a world where things go wrong. New York: Public Aûairs; 2014.

36. Mitchell A. Risk and resilience: from good idea to good practice. OECD Development Co-operation Working Papers No. 13, Paris: OECD Publishing; 2013. [Internet]

37. OECD. Guidelines for resilience systems analysis. OECD Publishing. 2014. [Internet]

38. WHO. Strengthening resilience: a priority shared by Health 2020 and the Sustainable Development Goals. WHO Regional Office for Europe. 2017. [Internet]

39. Almedom AM, Tumwine JK. Resilience to Disasters: A Paradigm Shift From Vulnerability to Strength. Afr Health Sci. 2008 Dec;8 Suppl 1(Suppl 1):S1-4. [PubMed]

40. Cutter SL, Barnes L, Berry M, Burton C, Evans E, Tate E, et al. A place-based model for understanding community resilience to natural disasters. Glob Environ Chang. 2008 Oct; 18:598-606. [Crossref]

41. Kais SM, Islam MS. Community Capitals as Community Resilience to Climate Change: Conceptual Connections. Int J Environ Res Public Health. 2016 Dec 6;13(12):1211. [PubMed] [Crossref] 
42. Dovers S, Handmer J. Uncertainty, sustainability and change. Glob Environ Chang. 1992 Dec;2(4):26276. [Crossref]

43. Brand FS, Jax, K. Focusing the meaning(s) of resilience: resilience as a descriptive concept and a boundary object. Ecol Soc. 2007;12(1):23. [nternet]

44. Adger WN. Social and ecological resilience: are they related? Prog Hum Geogr. 2000 Sep;24(3):347-64. [Crossref]

45. Dalziell EP, McManus ST. Resilience, vulnerability, and adaptive capacity: implications for system performance. Proceedings of the International Forum for Engineering Decision Making (IFED); Stoos, Switzerland. 58 Dec 2004. [Internet]
46. Woods DD. Essential characteristics of resilience. In: Hollnagel E, Woods DD, Leveson N (Eds.). Resilience engineering. Concepts and precepts. Aldershot, UK: Ashgate Publishing; 2006.

47. Woods DD. Four concepts for resilience and the implications for the future of resilience engineering. $R e$ liab Eng Syst Saf. 2015 Sep; 141(C):59. [Crossref]

48. Vogus TJ, Sutcliffe KM. Organizational resilience: towards a theory and research agenda. Proceedings of the IEEE International Conference on Systems, Man and Cybernetics; Montréal, Canada. 7-10 Oct 2007. [Internet]

49. Fairbanks RJ, Wears R, Woods
DD, Hollnagel R, Plsek P, Cook RI. Resilience and Resilience Engineering in Health Care. Jt Comm J Qual Patient Saf. 2014 Aug;40(8):376-83. [PubMed] [Crossref]

50. Haimes YY. On the definition of resilience in systems. Risk Anal. 2009 Mar;29(4):498-501. [Crossref]

51. Sutcliffe KM, Vogus TJ. Organizing for resilience. In: Cameron $\mathrm{K}$, Dutton JE, Quinn RE (Eds.). Positive organizational scholarship. San Francisco: Berrett-Koehler; 2003, pp 94110 .

52. Rudolph JW, Repenning NP. Disaster dynamics: understanding the role of quantity in organizational collapse. Adm Sci Q. 2002 Mar;47(1):130. [Crossref]

Please cite this article as: Koeva S, Rohova M. Health System Resilience: Concept Development. J of IMAB. 2020 JulSep;26(3):3251-3258. DOI: https://doi.org/10.5272/jimab.2020263.3251

Received: 30/08/2019; Published online: 29/07/2020

\author{
Address for correspondence: \\ Maria Rohova \\ Department of Health Economics and Management, Faculty of Public Health, \\ Medical University - Varna, \\ 55, Marin Drinov Str., Varna, Bulgaria \\ E-mail: mariarohova@abv.bg
}

